\title{
An Observation Tool for Effective L2 Pedagogy in Content and Language Integrated Learning (CLIL)
}

\author{
Rick de Graaff, Gerrit Jan Koopman, Yulia Anikina and \\ Gerard Westhoff \\ IVLOS Institute of Education, Universiteit Utrecht, Utrecht, \\ The Netherlands
}

In Europe, Content and Language Integrated Learning (CLIL) is becoming a popular and widespread practice of immersion education. In the Netherlands, for example, over 90 secondary schools offer a CLIL strand. Most CLIL teachers, however, are nonnative speakers of the target language, and do not have a professional background in language pedagogy. How, then, can these teachers effectively contribute to the target language development and proficiency of their students? In this paper we will discuss the findings of a study carried out in three secondary schools offering CLIL. The purpose of the study was to observe and analyse effective CLIL teaching performance facilitating language development and proficiency. The analysis was carried out by means of an observation tool for effective CLIL teaching, based on the following principles from second language pedagogy: (1) exposure to input; (2) content-oriented processing; (3) form-oriented processing; (4) (pushed) output; and (5) strategic language use. We will discuss how the CLIL pedagogy observed is related to content-based teaching and task-based language teaching, and provide recommendations for effective language pedagogy in CLIL. We will argue that not only CLIL teachers can profit from effective language-pedagogical approaches, but that language teachers can profit from effective CLIL approaches and experiences as well.

doi: $10.2167 /$ beb462.0

Keywords: CLIL, immersion education, language pedagogy, observation tool, teaching performance

\section{Introduction}

From the 1990s the impact of internationalisation and European integration has led to a need for greater levels of foreign language proficiency. The importance of having a broad range of school-leavers with a communicative proficiency in languages other than the mother tongue is continuously stressed by the EU members. However, as Marsh (2002) states, a delivery gap between foreign language curricula and outcomes in terms of learner language attainment still needs to be bridged.

In order to achieve a greater degree of plurilingualism and to make Europe the most competitive and knowledge-based economy in the world, the European Commission developed an Action Plan for language learning and linguistic diversity and set up an ambitious undertaking to enable all Europeans to communicate in two community languages in addition to their 
mother tongue, known as the MT +2 formula (Marsh, 2003). In providing educational solutions to the issue of achieving higher levels of language learning, practical approaches to improving the quality of language teaching and learning have been launched. These experiments have highlighted the need to focus on meaning alongside form in order to achieve better practice among learners. The hallmark of these initiatives was an integrated, processorientated approach to language learning (Marsh \& Langé, 2000). The essential constituents for success lay in exposure to and interaction based on authentic and functional input (Baker, 1993; Genesee, 1987). The need to provide more opportunities for foreign language exposure and interaction resulted in developing additional, integrated opportunities for foreign language use within the standard school curriculum (Marsh, 2005).

In order to create extra opportunities for young people to have exposure to functional environments for language acquisition and learning, integrating language with non-language content, in a dual-focussed learning environment, has been experimented and implemented as a solution (Marsh, 2005). Success with this approach in international schools and effective implementation in other contexts, for example in Canadian immersion schools, has led to support of its introduction into European mainstream education (Baetens Beardsmore, 1993). Thus, a pragmatic and professionally accepted innovative approach to foreign language learning has emerged throughout Europe to enhance the value of European linguistic diversity and achieve sustainable learners' outcomes (Wolff, 2000). This approach came to be termed Content and Language Integrated Learning (CLIL).

European bilingual educational developments have often been inspired by Canadian immersion education in which English-speaking students receive subject-matter instruction via French. The results of research in these programmes, however, indicate that while students' comprehension ability is comparable to that of their native francophone peers, they do not reach full native-like linguistic competence free oral production (Baker, 1993; Cummins \& Swain, 1986; Genesee, 1987; Pawley, 1985; Swain \& Lapkin, 1985). Students in French immersion programmes also struggle with persistent morphological, syntactic and lexical inaccuracies (Lyster, 1984). In an effort to address this issue, several researchers have carried out studies to investigate the effects of different types of form-focused instruction and corrective feedback within French immersion programmes (Harley, 1993; Lyster \& Ranta, 1997; Lyster, 2004; Obadia, 1996). We will further address this issue in the following section on the facilitation of form-focused processing and output production.

\section{The CLIL Model in the Netherlands}

CLIL is offered in a variety of forms within Europe. According to the information network on education in Europe (Eurydice, 2005 www.eurydice.org), in the majority of countries schools offer a form of CLIL in which subjects are taught in at least two different languages - the official state language (or one such language if there is more than one) and a foreign language. This applies to the Netherlands, in which the language of instruction employed in addition to Dutch is generally English. 
As illustrated by Maljers and Wooning (2003), over the last 5 years CLIL in the Netherlands has seen a dramatic growth, starting from one school in 1989 to over 90 secondary schools in the school year 2006-2007. The official guidelines by the Ministry of Education and the Inspectorate indicate that $30-50 \%$ of the curriculum may be taught in English. The provision of CLIL is expected to be cost-effective and not to minimise language proficiency in the Dutch language, and it does not demand extra time in the curriculum.

The main goals for students intending to follow CLIL in the Dutch context are formulated as follows:

(1) a better command of a language;

(2) preparation and orientation to a more international society; and

(3) preparation to study abroad or for courses taught in English.

Dutch students can start CLIL at the very beginning of secondary education (12-13 years old) with subjects like History, Geography and Biology. Types of subjects may vary between schools. However, these subjects need to include at least one subject from the social sciences, one from the natural sciences and one creative subject (such as drama, arts \& crafts, and physical education). Dutch CLIL students are required to participate in the national final examination, which is in Dutch for all school subjects (with the exception of foreign language subjects, obviously). Therefore, most schools switch to Dutch as the target and primary communication language for a majority of subjects in the upper level of secondary education.

Schools introducing CLIL usually do so with their regular Dutch staff. Interested teachers are selected and trained during a two-year period of inservice training courses. Most schools offer teachers courses ranging from classroom English to advanced English language programmes. Training is usually supported in-school by the English teachers. In addition, there are several institutions in the Netherlands that offer training for content and language integrated teaching, focusing mainly on the development of teachers' language proficiency.

In her evaluation of Dutch CLIL, Huibregtse (2001) has shown that learning outcomes are encouraging and defuse fears about negative effects of CLIL. The data show that the students who have followed a CLIL curriculum reach higher levels of proficiency in English than their peers, without any negative effects on their academic proficiency in L1 or on other school subjects. De Bot (2002) stresses that both teachers' and students' attitudes are generally positive, as they consider this type of education as an interesting challenge rather than an obstacle.

\section{Research Questions}

Although much attention has been paid to the proficiency level in English of CLIL teachers and to the selection and adaptation of subject matter textbooks for CLIL, national CLIL evaluations indicate that little attention is paid to the pedagogic repertoire of CLIL teachers and how this contributes to the pupils' target language proficiency (see Maljers \& Wooning, 2003). 
Therefore, in this paper we aim to investigate characteristics of effective CLIL teaching performance and relate these to theoretical principles in second language acquisition. The specific research questions are:

(1) What CLIL teaching performance indicators can be derived from theoretical assumptions about effective language teaching and learning?

(2) What instances of effective teaching performance in CLIL lessons can be identified by means of an observation tool based on assumptions of effective language teaching performance?

(3) What practical recommendations can be provided to both CLIL and FL teachers concerning effective language pedagogy?

The aim of the study reported here is not to quantitatively analyse or qualitatively evaluate CLIL practice, but to detect and describe instances of effective CLIL teaching performance based on language teaching performance indicators.

\section{CLIL Teaching Performance Indicators}

Consistent with communicative, task-based and content-based language teaching, CLIL stresses the idea that any fluency in the use of a target language can be achieved best by its use as a functional medium of communication and information, and not by making it the object of analysis in class. Recent instruction taxonomies make a broad distinction in terms of the direction of the learner's focal attention between form-focused instruction (FFI) and meaning-focused instruction (MFI) (Ellis, 1999, 2001; Norris \& Ortega, 2000; Spada, 1997; Williams, 2005). In MFI, the learner's focal attention is predominantly on the communication of relevant meanings and authentic messages (Ellis, 1999, 2001). Examples of MFI can be found in the Natural Approach to L2 teaching (Krashen \& Terrell, 1983) and other forms of communicative language teaching (CLT) (Nunan, 1989; Prabhu, 1987), immersion programmes (Johnson \& Swain, 1997; Johnstone, 2002), in content-based second language programmes, in CLIL (cf. Baker, 2006; Wesche \& Skehan, 2002) and also in proposals for task-based instruction (cf. Crookes \& Gass, 1993; Ellis, 2003, 2005).

The major difference between teaching CLIL and teaching the subject in the mother tongue is the fact that CLIL involves additional language learning objectives and specific opportunities for communication and language use. The reasons for the integration of language and content have emerged from diverse outcomes of significant experience in foreign language teaching and bilingual education:

(1) Communicative language teaching: language is acquired most successfully when it is learned for communication purposes in meaningful and significant social situations (Brumfit \& Johnson, 1979).

(2) Content-based language teaching: the integration of content and second language instruction provides a substantive and functional basis and exposure for language teaching (Cummins \& Swain, 1986; Echevarria et al., 2000; Genesee, 1987). 
(3) Task-based language teaching: exposure, use and motivation in functional and relevant activities are prerequisites for successful language learning (Bygate et al., 2001; Ellis, 2003; Willis, 1996).

From the Dutch perspective, the main aim of CLIL is functional, that is, to develop proficiency in a foreign language alongside knowledge of a nonlanguage subject area. Taking authentic material as a starting point, it leads to a task-based use of language that is organised around the understanding and interaction of subject-related topics.

Effects of teaching performance on language acquisition in content-based classrooms have been extensively studied in Canadian immersion studies. For example, research by Lyster and Ranta (1997) and Lyster (2004) has examined the 'negotiation of form' in immersion classrooms, by comparing corrective feedback and learner uptake. Lyster and Ranta studied the frequency and distribution of six different feedback types used by teachers, in relation to the frequency and distribution of different types of learner uptake. They found that teachers most frequently used recasts (that is, corrective rephrasing), whereas it was concluded that this feedback type was less effective with respect to eliciting student-generated repair (that is, self-correction). Lyster (2004) argues that in immersion classrooms recasts are problematic in the sense that learners often do not notice the teacher's attempt to draw the learners' attention to language form because of the primary focus on meaning.

Other research in French immersion programmes has also explored how to draw learners' attention to language form within meaning-based interaction. For example, Swain and Lapkin (2003) have asked learners to reflect on their language use through collaborative activities in which they talk and reflect upon the language they need in order to express their meaning. The findings from this research indicate that this collaborative talk provides students with a better understanding of correct language use.

Our conceptualisation of effective teaching performance for language acquisition in CLIL includes attention to such features as functional communication, simultaneous attention to form and meaning, and type of corrective feedback, within a broader framework of three essential conditions for language acquisition - exposure, use and motivation (Willis, 1996: 11). Those essential conditions have been further elaborated in an observation tool for this study according to five basic assumptions related to effective language teaching performance.

\section{Teacher facilitates exposure to input at a (minimally) challenging level}

There seems to be a broad consensus that extended exposure to meaningful and functional foreign-language input is a crucial, although not sufficient, prerequisite for foreign-language acquisition (Klein, 1986; Krashen, 1985; see de Graaff \& Housen, in press, and Housen \& Pierrard, 2005, for a more detailed overview).

Connected to this assumption, before a lesson a CLIL teacher is expected to select and tailor input material in order to make it challenging but comprehensible for learners. Two types of scaffolding can be distinguished 
during the lesson, namely on content and/or language of the input material and content and/or language of teacher talk.

In the observation tool, this category consists of the following indicators for effective teaching performance:

1.1. text selection in advance

1.2. text adaptation in advance

1.3. adaptation of teacher talk in advance

1.4. text adaptation during teaching

1.5. fine-tuning of teacher talk

\section{Teacher facilitates meaning-focussed processing}

Mere exposure to language is not enough. There is little doubt that exposure to input is only effective if the input is processed for meaning. Processing in working memory and relating/connecting to knowledge from long-term memory has to take place for input to be storable and retrievable (see, e.g. Johnson, 1982; Skehan, 1998; Wesche, 1993).

Connected with this assumption, a teacher can be expected to stimulate content-processing of oral or written input by giving special tasks that involve learners in grappling meaning (trying to make sense of whatever they hear or read). The teacher should check whether the meaning of the input has been comprehended sufficiently. If meaning is processed insufficiently or erroneously, the teacher might give some kind of support. Supplementary exercises on the related content features of input can be performed in this category as well.

In the observation tool, this category consists of the following indicators for effective teaching performance:

2.1. stimulating meaning identification

2.2. checking meaning identification

2.3. emphasising correct and relevant identifications of meaning

2.4. exercises on correct and relevant identifications of meaning

\section{Teacher facilitates form-focussed processing}

There is little agreement on the role of grammar or so-called 'form-focused instruction' (see, for an overview, Burgess \& Etherington, 2002; Doughty, 2003). However, an extensive body of research (as summarised, e.g. by Housen \& Pierrard, 2005) supports a role for formal instruction in order to enhance learner hypothesis formation on language structure. Instruction that is supposed to direct learner attention to form-related aspects of the input is characterised as 'Focus on Form', to be distinguished from isolated, discretepoint grammar instruction and exercises, which is labelled 'Focus on Forms' (Doughty \& Williams, 1998; Long, 1991).

With reference to this assumption, a CLIL teacher can employ activities aimed at awareness-raising of language form, thus making learners conscious of specific language features. The teacher might indicate and direct learners' attention to correct and incorrect uses of form, give examples of such uses, thus facilitating implicit or explicit noticing of language form. In giving 
corrective feedback the teacher might employ implicit (e.g. clarification requests, recasts) or explicit (e.g. explicit correction, metalinguistic comment, query, advice) techniques for focussing on form, as well as nonverbal reactions.

In the observation tool, this category consists of the following indicators for effective teaching performance:

3.1. facilitating noticing of problematic and relevant language forms

3.2. providing examples of correct and relevant language forms

3.3. correcting use of problematic and relevant language forms

3.4. explaining problematic and relevant language forms, e.g. by giving rules

3.5. having pupils give peer feedback

\section{Teacher facilitates opportunities for output production}

Ample research has supported the facilitating and stimulating role of output production. According to the output hypothesis (De Bot, 1996; Swain, 1995; Swain \& Lapkin, 1995), output production can enhance fluency, by raising the learner's awareness of language deficits, thus increasing their motivation for learning. Pushed output contributes to Focus on Form and gives the teacher or the communication partner the opportunity to provide corrective feedback (Lyster \& Ranta, 1997).

With reference to this assumption, in promoting output production in the target language a CLIL teacher can encourage learners to react and ask questions aimed at functional output as well as stimulate interaction between learners in the target language. Different interactive formats (e.g. group, pair work) might be implemented to facilitate meaningful communication in English. Through instructions and/or corrections the teacher can guide learners to use English exclusively in the lesson. Corrective feedback by teachers or peer-students might stimulate correct use form/meaning connections by learners. The teacher can use a diverse range of activities for further exercising essential aspects of form/meaning use.

In the observation tool, this category consists of the following indicators for effective teaching performance:

4.1. asking for reactions

4.2. asking for interaction

4.3. letting students communicate

4.4. stimulating the use of the target language

4.5. providing feedback, focusing on corrected output

4.6. organising written practice

\section{Teacher facilitates the use of strategies}

Language learners can compensate for deficiencies in receptive knowledge by applying reading and listening strategies, such as inferring unknown elements and using prior knowledge (Westhoff, 1991a, 1991b). To accommodate deficiencies in productive competence, learners develop communication 
skills such as negotiating meaning, avoidance and paraphrasing (Bialystok, 1990; Littlemore, 2001; Poulisse, 1989).

With reference to this assumption, a CLIL teacher should be able to assist learners to overcome their language and content comprehension and communication problems, by developing a repertoire of receptive and productive compensatory and communication strategies. Scaffolding and reflection onthe-spot is considered of great importance, when the teacher should be able to suggest to the learners an effective path (use of strategies) for resolving comprehension or language use problems they have encountered.

In the observation tool, this category consists of the following indicators for effective teaching performance:

5.1. eliciting receptive compensation strategies

5.2. eliciting productive compensation strategies

5.3. eliciting reflection on strategy use

5.4. scaffolding strategy use

According to Westhoff (2004), these five assumptions can be considered as the basic ingredients for effective language learning and teaching activities. Westhoff's 'SLA penta-pie' (named after a five-section pie chart) is illustrated in Figure 1 and forms the theoretical basis for the observation tool in this study.

\section{Effective Teaching Performance in CLIL Lessons}

In order to find practical evidence for teaching performance promoting learner language acquisition within CLIL contexts, a research instrument in the form of an observation tool was constructed according to the basic

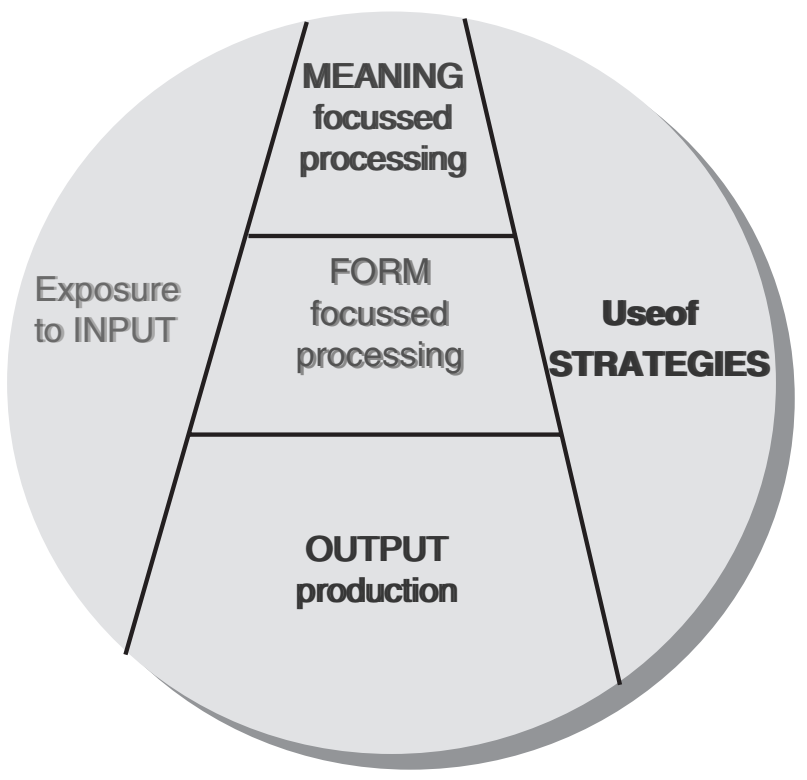

Figure 1 The SLA 'penta-pie'

Adapted from: Westhoff (2004) 
assumptions of the SLA 'penta-pie'. The observation tool was piloted on seven CLIL lessons by CLIL teacher trainees, in order to validate its usability and coverage. Subsequently, the observation tool was used to analyse a set of CLIL lessons from a variety of school subjects in three Dutch CLIL schools.

\section{Procedure}

Nine lessons from three Dutch CLIL secondary schools were observed, video-taped and analysed by means of the observation instrument for effective pedagogy. The three schools belong to the same consortium of schools and are medium-sized Dutch schools of about 1200 students each. Each school has a CLIL stream of about 300 students per school. The schools implemented a CLIL programme about six years ago. The sample for this study consisted of nine lessons from the following subjects: History (three male teachers), Geography (one male teacher), Biology (one female teacher), Maths (one female teacher), Arts and Crafts (one female teacher) and English (two female teachers). We observed one lesson per teacher.

All teachers had at least five years of teaching experience and two years of CLIL experience. None of them were native speakers, except for one teacher of English. They had all passed the Cambridge Proficiency Exam. The lessons all lasted 50 minutes; the students' ages ranged from 12 to 17 years. See Table 1 for further specifications.

All videotaped lessons were observed and analysed by at least two researchers. Any doubts concerning the qualification of specific excerpts were discussed and agreed upon in the research team, consisting of four researchers.

In order to gain further clarity about the teachers' intentions, interviews were conducted immediately after the lessons observed. The interviews lasted for about 20 minutes, were recorded, and addressed issues such as: the amount of language teaching within the subject lesson, the role of the foreign

Table 1 Teachers, CLIL lessons and EFL lessons observed in this study

\begin{tabular}{||l|l|l|c||}
\hline \multicolumn{1}{|c|}{ Subject } & \multicolumn{2}{c|}{ Teacher } & \multicolumn{2}{c|}{ Students } \\
\cline { 3 - 4 } & & Year of CLIL education & Age \\
\hline History & History Teacher 1 & First year & $12-13$ \\
\hline History & History Teacher 2 & Second year & $13-14$ \\
\hline History & History Teacher 3 & Second year & $13-14$ \\
\hline Geography & Geography Teacher & Third year & $14-15$ \\
\hline English & English Teacher 1 & Fourth year & $15-16$ \\
\hline English & English Teacher 2 & Fifth year & $16-17$ \\
\hline Maths & Maths Teacher & First year & $12-13$ \\
\hline Biology & Biology Teacher & Third year & $14-15$ \\
\hline Arts and Culture & Arts and Culture Teacher & Third year & $14-15$ \\
\hline
\end{tabular}


language in preparing lessons, adapting teacher talk and materials from a language focus, etc. The outcomes of the interviews helped the observers analysing the videotaped lessons for certain categories.

\section{Results}

In general it was found that, over all lessons observed, teachers used almost the whole range of effective teaching performance indicators. Although not every teacher used all performance subcategories in all the observed lessons, consistent and useful examples were found for almost every subcategory. As the aim of this research was to detect examples of effective CLIL pedagogy and to validate the instrument, the observations were not used to provide a quantitative analysis of the school, a department or individual teachers, or to evaluate the quality of these.

In the description of the data below, we will indicate occurrences of specific performance indicators. For each category first a short explanation of the performance indicator is given, followed by an example (when available) found in one of the lessons. At the end of each main category we give a global overview of occurrence and dispersion.

\section{Teacher facilitates exposure to input at a minimally challenging level}

Text selection in advance

Performance indicator: When choosing a 'text', the teacher pays attention to both the language level of the text and the content in such a way that it is just beyond the expected level of the students. Text in this context means written texts, videos and audios, sites, etc.

No examples of this performance indicator were observed.

\section{Text adaptation in advance}

Performance indicator: The teacher has adjusted the selected text in such a way that the level of the text is just beyond the expected level of the students. Text here means the same as above. The teacher can choose from a variety of methods: offer a list of core concepts, use synonyms and/or translations of 'difficult' words, clarify text structure by indicating headings, paragraphs, key words, etc., use pictures to support the text, visualise the text using diagrams, summarise the text orally or written, etc.

History Teacher 3 formulates preparation/process activities in the form of steps to be taken during the lesson highlighting them on the board; gives instruction how to work in steps and find an answer to the main question. In the Geography lesson the teacher selects exercises with a growing level of difficulty and explains the sequence of tasks.

\section{Adaptation of teacher talk in advance}

Performance indicator: The teacher has prepared teacher talk in such a way that it is just beyond the expected level of his/her students. Words or sentences might be 'too difficult' for the students and s/he can think of ways 
to adjust these. Such may be done by using body language, simple sentence structures, giving synonyms, descriptions, translations of difficult words, etc.

History Teacher 1 explains how Stonehenge was built and uses simple structured sentences and language. The question being discussed is transportation of heavy materials to Stonehenge. The teacher presents three theories. One theory is explained as follows: ' . . . that is the theory that I heard as well. They used logs, "boomstammen", and they put all these logs next to each other, and they put the stone on it and they roll and they put the log at the backside of the stone and put it in front and they roll (he visualises logs next to each other and the process of replacing them), ... Do you believe that one?' After which he continues to ask the students which of the three theories really holds.

\section{Text adaptation during teaching}

Performance indicator: The teacher adapts his/her selected texts during the lesson after realising it is above comprehension level. Techniques used include: summarising, paraphrasing, translating synonyms, asking clarifying questions, gestures and body language, board drawings, etc.

The following excerpt shows that in the geography lesson the concept of 'infrastructure' is not clear to the students and how the Geography Teacher decides to adapt his language: 'Okay, so infrastructural works for instance, sewers is a part of the infrastructure. Any other things in the infrastructure for instance?...' (Student fails to answer). 'What kinds of infrastructure do we have here in the Netherlands? Come on, wake up. Floris? What kind of works of infrastructure do we have in the Netherlands? How did you get here ... this morning?' Student: 'By bike'. Teacher: 'So what did you need to ride your bike?' Student: 'Bike'. Teacher: 'Yeah, your bike that's the first thing. A house to go away from, to part. But also ... in between, come on.' Student: 'A road.' Teacher: 'A road, a cycle-path for instance. That's part of infrastructure. Telephone lines, telephone network, eh ehm, waterworks, things like that. Those are all infrastructure.'

\section{Tuning of teacher talk}

Performance indicator: The teacher adapts his/her own language after realising or suspecting that this is beyond the students' level. S/he uses the same techniques as mentioned in 'Adaptation of teacher talk in advance'. It is also possible that the teacher deliberately first introduces a word or concept in a challenging way and then gives the more easy words (or vice versa).

History Teacher 1 translates the word 'statue' into Dutch and he acts out the word 'boring'. History Teacher 2 makes the gesture for money when he wants to indicate that the colonialists 'wanted to fill their wallets'.

\section{Discussion}

Of course it is difficult to find examples for the above subcategories 'Text selection in advance', 'Text adaptation in advance' and 'Adaptation of teacher talk in advance' by classroom observations and video analysis, as these subcategories are about preparatory, and therefore non-observable teaching performance. Examples found for these subcategories could only be detected after the teachers had referred to their preparation in the interviews. In the interviews several teachers indicate that they are aware of these categories and 
that they do pay attention to the language level of their language as well as in selecting texts.

The lessons observed show that many teachers use 'Text adaptation during teaching' very often. Several teachers use 'Tuning of teacher talk' very often.

\section{Teacher facilitates meaning-focussed processing}

Stimulating meaning identification

Performance indicator: The teacher sets tasks for the students that help them to identify the meaning of important concepts. Tasks such as filling in plans, using organisers or matching exercises all aim at a better understanding of the contents of the lesson.

History Teacher 2 stimulates students to identify meaning in the following way:

I want an explanation for this sort of cartoon. An explanation. Think of an explanation; why does it say 'join or die' take a close look at the snake... auses... Robin can you answer it, can you explain the cartoon?

\section{Checking meaning identification}

Performance indicator: The teacher checks whether students have understood the most important concepts or words. Simple questions such as 'Do you understand that?', 'Do you agree with that?', 'Do you believe it' or 'Do you think the first description is correct or the second?' help the students to rethink the concepts. Checking meaning identification not only goes for the content level of the lesson, but also functions at the classroom organisational level, as is shown in the following example.

The Maths Teacher says to a student: 'Oh boy, you can hand it in tomorrow. Yes? Ok? Do you understand what I am saying?'

\section{Emphasising correct and relevant identifications of meaning}

Performance indicator: The teacher gives or emphasises the correct meaning of important concepts or words when s/he notices or suspects that students do not fully master these concepts.

The Geography Teacher asks the question: 'Is there also an economical reason for Ghana to stimulate tourism? Please think about it for a while.' After the student has answered the question the teachers emphasises as follows: 'Right, right, ok. So the problem of debts is a fierce problem in Ghana also. That is the reason why it is a LEDC, less economically developed country.'

\section{Exercises on correct and relevant identifications of meaning}

Performance indicator: The teacher sets extra tasks that anchor identifications of meaning that have already been identified. S/he usually does so when s/he considers it important for the students to remember these concepts. One can think of the following tasks: fill in plans related to a certain text or topic, construct your own order of the contents of the topic, match pictures with the concepts, make a web-diagram, but also make sure that students write the 
difficult words per lesson e.g. in the back of their notebooks or make them work with personal files.

The Biology Teacher has explained human teeth formation and annotated them in a tooth-formula. Students then make two tooth-formulas of family members, friends etc. in order to anchor the concept of a tooth-formula and the labels for various teeth. This is how she introduces the task: '... Okay, and what we are going to do, is write down the different kind of teeth you can do it in colours, or just make small arrows. Here we are going to write in the orange colour the "incisors". Next to it in white, we are going to write down the "canines" and at last, I have yellow not a very clear ..., oh, let's make it green that's better, the green ones are the "molars". "de kiezen". Okay, how many incisors do we have?'

\section{Discussion}

In the lessons observed we found several examples in all four subcategories. Several teachers often check identification of meaning. They often use the following three checks:

- Clarification: Is it clear? Has everybody got that?

- Validation: How did you know that? Why do you think it is different here?

- Confirmation: Do you agree? What can you suggest?

Emphasising correct and relevant identifications as well as exercising and stimulating identifications occur in some cases.

\section{Teacher facilitates form-focussed processing}

\section{Facilitating noticing of problematic and relevant language forms}

Performance indicator: The teacher points out language forms and structures that are essential for both understanding and oral or written production of the content. S/he may expect that the forms will be both relevant and challenging for the students. Forms and structures may include a large variety e.g. phrasal verbs, tenses, word order, sentence structure or chunks.

English Teacher 1 points out to her students that they have to use certain time structures for their presentations: 'So I suggest you to not only prepare your talk, but really pay attention to the time-structures. Why is that? Because when you talk about the things that happened in the past, what kind of time structure do you use?'

\section{Providing examples of correct and relevant language forms}

Performance indicator: The teacher emphasises and/or gives examples of language forms and structures that are also relevant in other contexts.

The Maths Teacher said: 'You do the revision on page 14, so you revise (stressed) page 14.'

\section{Providing feedback on use of problematic and relevant language forms}

Performance indicator: This subcategory focuses on correcting incorrect language production (both oral and written) from the students. The teacher makes a judgement whether the classroom situation and the language 
proficiency level is such that a positive effect of the correction may be expected. The following subcategories may be used.

Explicit correction. The teacher repeats the incorrect language production and corrects the mistake explicitly.

Recast. The teacher repeats the incorrect language production and corrects the mistake implicitly.

Metalinguistic feedback. The teacher gives the grammatical rule.

In one of the lessons observed we found a student saying to History Teacher 2: 'They didn't had anything ...' and the teacher correcting 'They didn't have anything indeed ...'.

Explaining problematic and relevant language forms, e.g. giving rules

Performance indicator: The teacher explains a rule when s/he expects that this explanation promotes correct language production or recognition in the future.

No examples of this performance indicator were observed.

\section{Having pupils give feedback}

Performance indicator: The teacher signals an incorrect language production and makes another student react to this. Another way of doing this is having students correct each other's language production.

Such an example is found during the lesson of History Teacher 2. After the teacher has collected some content-based reactions from his students about things fellow students had written down, he continues: 'Could you please check the English used by your fellow classmates and maybe write down some remarks about it?... This is wrong sonny! ... Let's see if you can be an English teacher.' After this has been done he says: 'Who would like to mention one mistake? Iris? Another mistake? An important one?'

\section{Discussion}

We found no teachers explaining problematic and relevant language forms. Of the other four subcategories we found few examples. This is contradictory to the general picture from the interviews in which a lot of teachers stressed the importance of giving corrective feedback on students' language utterances. On the other hand, many teachers also stressed that they are subject teachers in the first place, and that explaining forms and giving rules is the domain and expertise of the EFL teacher in the first place.

\section{Teacher facilitates output production}

\section{Asking for reactions}

Performance indicator: In a whole-class situation the teacher asks individual students questions about the contents of the lesson or about important concepts. S/he makes sure that an individual student answers his/her question each time.

While studying a cartoon, History Teacher 2 says: 'I want an explanation for this sort of cartoon. An explanation. Think of an explanation; why does it say 
"join or die"? Take a close look at the snake ... Pauses ... Robin can you answer it, can you explain the cartoon?'

\section{Asking for interaction}

Performance indicator: In a whole-class situation the teacher proceeds as described above. The difference is that $s /$ he encourages students to react to each others' reactions. Questions like: 'would you agree with what X just said?' and 'How would you rephrase what $X$ just said?', are good examples for this category.

History Teacher 2 encouraged fellow students to react in the following way: 'Maybe there is another person, who wants to add something ... cause frankly it is a tiny weeny answer, isn't it?'

\section{Letting students communicate}

Performance indicator: The teacher sets small assignments which encourage students to talk with one another in small groups or pairs. The teacher uses various combinations of individual, pair and team work to accomplish a joint project (presentation, group report, presenting flyers).

English Teacher 1, after having explained the purpose and procedure of a student assignment, tells them to form small groups and start working on the preparation of oral presentations on city trips.

History Teacher 3 asks his students to sit together in groups of four and discuss the assignments the have done for homework.

\section{Stimulating the use of the target language}

Performance indicator: The teacher uses the target language continuously and stimulates students to do so as well.

History Teacher 2 at the beginning of the lesson: ' . . a and I think I hear some Dutch. You know what we agreed on ...'

The Arts and Culture Teacher during the lesson when students are talking in Dutch: 'Do you all have enough space?' Student: (inaudible). Teacher: 'Okay, and now in English. Try to translate it.'

\section{Providing feedback on language use, focusing on corrected output}

Performance indicator: Like 'Providing feedback on use of problematic and relevant language forms' this category focuses on correcting incorrect language production from the students, both oral and written. The teacher makes a judgement whether the classroom situation and the language proficiency level is such that a positive effect of the correction may be expected. The difference is that the teacher prompts the students to give the correct language utterance.

The following subcategories may be used.

Repetition. The teacher repeats the student's mistake without correcting it. The teacher highlights the mistake by adjusting intonation in such a way that $\mathrm{s} / \mathrm{he}$ 'forces' the student to repeat his utterance in a correct way.

Elicitation. The teacher repeats the incorrect utterance, but leaves out the mistakes and replaces that by a question mark or simply a 
'mmm'. In this way the student is asked to 'fill in the blank' and thus provide the correct answer.

Clarification request. The teacher directly asks the students what he means with his incorrect utterance in such a way that it is clear that the student produced incorrect language.

At the beginning of a Geography lesson, a student says: 'Sir, I've made my homework but I was so stupid that I didn't brought it with me.' Geography Teacher: 'You didn't do what?' Student: 'I did my homework'. Teacher: 'Oh, but you didn't bring it?' Student: 'No, I didn't bring it.'

\section{Organising written practice}

Performance indicator: The teacher sets written assignments for the students in which the students have to process the subject contents.

History Teacher 2 first explains a theoretical concept and then he says: 'Please write down in your notebook what you heard what I just said and try to make it your own sentence.' The same teacher also encourages his students to give peer feedback in the following way. First students are asked to write down their opinion about a topic after which they exchange notebooks with their neighbour who will comment on the content of what has been written. The notebooks are then passed on to a third student who gives feedback on both what the first and the second student have written.

\section{Discussion}

We very often found examples of 'Asking for reactions' and 'Asking for interaction'. As teacher-guided discussion is a very common instructional format in Dutch classrooms, this is not surprising. Also, in Dutch CLIL classes a strong emphasis is put on speaking English all the time, which is why we found several examples of 'Stimulating the use of the target language'.

In 'Providing feedback ...' we found a few examples. This is a similar pattern to that of the closely related category 'Providing feedback on use of problematic and relevant language forms.' Only a few examples were found of 'Organising written practice', as writing usually takes place as homework instead of an in-class activity.

\section{Teacher facilitates the use of strategies}

\section{Eliciting receptive compensation strategies}

Performance indicator: When students face problems understanding texts the teacher helps them by asking questions that stimulate the students to use reading strategies, such as: helping questions related to pictures, photos, cartoons, etc. that can be found in the text; questions related to titles, subtitles, headlines, bold or italic words, indentations; questions about discourse markers or text-structure words; questions related to the overall text structure of the text; questions related to how to deal with difficult or unknown words, etc. All these strategies help the reader to understand meaning, structures and relationships between different parts of the text.

English Teacher 2 shows a Dutch poster with a Dutch message on it. She, being English herself, explains to her students that although her Dutch enables her to understand the words as such, she could only understand the meaning 
by looking at the poster as a whole and combining the picture and the organisation that published it.

\section{Eliciting productive compensation strategies}

Performance indicator: The teacher helps the students during their oral language production when they fail to express themselves in a correct way. $\mathrm{S} /$ he will stimulate them to keep on talking and e.g. describe things in their own words or use gestures or body language to make clear what they want to say. Sentences like 'Describe this in your own words' or 'Please show me with your hands what it looks like' fall under this category. Stimulating the use of dictionaries can also be part of this category.

English Teacher 2 elicits a compensation strategy in the following way. When a student fails to define the difference between a commercial and a non-commercial message, she asks her: 'Can you give me an example of a non-commercial and a commercial message?'

\section{Eliciting reflection on strategy use}

Performance indicator: The teacher explicitly discusses the advantages for the students of using compensation strategies mentioned in the two categories above.

History Teacher 1 has the following way of reflecting on this strategy use. In his lesson the Dutch word 'steiger' (scaffold) is met. The teacher then continues: 'Yes, who knows the word for "steiger". Timo you know it? I think it "stairs", but you a better word? I forgot to look it up. Oh oh.' Pupil: 'Scaffold'. Teacher: 'Did you know it or did you look it up or did you ask your parents?'

\section{Scaffolding strategy use}

Performance indicator: When students have to prepare a presentation in class, the teacher suggests ways of how to prepare this from a language point of view. S/he makes them realise which vocabulary or chunks they might need while giving the presentation.

English Teacher 1 helps her students prepare for their presentation (on travelling to another country) by telling them: '... and if you have finished that, which shouldn't take too long, because you needn't write down everything, you are going to get this small white card, on which you write down your 'slot' they say. That means that the one item you will be discussing, is going to be written down in telegram style. Cos you are going to present it, you are not going to read it aloud. ... If in preparing you need help there are dictionaries here and you know these cards, we have been working with them last year, they give you suggestions of sites and languages that you use when you go to a particular place that is worth seeing or visiting. So that is a help as well.'

\section{Discussion}

Whereas we have rarely found examples of 'Eliciting receptive compensation strategies', our data often showed examples of teachers eliciting productive compensation strategies helping students while producing spoken language in class. We have sometimes found examples of teachers reflecting 
on effective strategies as well as a teacher of English who stimulated students to make sure that they prepared their speeches from a language point of view.

\section{Conclusions and Practical Recommendations for CLIL Teaching}

This research has aimed at finding practical evidence for theoretical assumptions on effective teaching performance directed at language acquisition in CLIL contexts. For this purpose, teaching performance indicators have been formulated, derived from assumptions about effective language teaching. Those performance indicators have been integrated in an observation tool for effective CLIL teaching practice.

In the CLIL lessons analysed in this study sufficient evidence was found for most subcategories of the five main indicators for effective language teaching performance, as in:

(1) Teachers facilitate exposure to input at a (minimally) challenging level by selecting attractive authentic materials, adapting texts up to the level of the learners and scaffolding on the content and language level by active use of body language and visual aids.

(2) Teachers facilitate meaning-focussed processing by stimulating the learners to request new vocabulary items, check their meaning, use explicit and implicit types of corrective feedback on incorrect meaning identification, and practice through relevant speaking and writing assignments.

(3) Teachers facilitate form-focussed processing by giving examples, using recasts and confirmation checks, clarification requests and giving feedback (sometimes including peer feedback). No evidence was found of CLIL teachers providing explicit form-focused instruction, e.g. by explaining rules.

(4) Teachers facilitate output production by encouraging learners' reactions, working in different interactive formats and practising creative forms of oral (presentations, round tables, debates) and written (letters, surveys, articles, manuals) output production, suggesting communicatively feasible tasks, giving the learners enough time for task completion, encouraging learners to speak only in English, providing feedback on students' incorrect language use and stimulating peer feedback.

(5) Teachers facilitate the use of compensation strategies by stimulating students to overcome problems in language comprehension and language production, reflecting on use of compensation strategies, and scaffolding on-the-spot strategy use.

We can conclude, then, that the CLIL lessons observed in this study show instances of effective language teaching performance. That is, the subject teachers in the study perform at least incidentally as effective language teachers.

Subcategories for which little evidence was found in the lessons observed were facilitating noticing of problematic and relevant language forms and 
explaining problematic and relevant language forms, e.g. by giving rules. Interestingly, few instances of these subcategories were observed in the two EFL lessons as well. This might be a coincidence, because of the practice-based orientation of both lessons, in combination with the advanced proficiency level of the 4rd/5th year CLIL students in the observed EFL lessons. CLIL teachers as well as EFL teachers in this study, then, show other performance for facilitating form-focussed processing than giving form-focused instruction or explaining grammar rules.

The testing of the observation tool has proven its theoretical relevance for the basic assumptions for effective language teaching. From a language acquisition point of view, a natural progression from this research would be to ascertain if there are any long-term impacts of effective CLIL teaching performance on learners' language attainment.

\section{Further Developments and Implementation of the Observation Tool}

The results of this research, the first practical experiences and teachers' reactions in the interviews related to this study, show that teachers appreciate the tool as useful for expanding their teaching repertoire in a CLIL context. The tool might be further developed and implemented as a practical instrument in CLIL teacher training (e.g. pre-service/in-service, peer-coaching) and self-reflection of individual CLIL teachers (e.g. in professional development plans and performance reviews). For that purpose, a cd-rom has been edited and produced containing video-clips that show examples of effective CLIL teaching performance in all subcategories found. The examples are accompanied by explicit 'do-statements' for all subcategories and suggestions for classroom activities. The cd-rom and the observations instrument have been distributed among all CLIL schools in the Netherlands, and are used in pre-service training, in-service training and peer coaching sessions in our institute for teacher training.

Although the observation tool was developed for effective language teaching performance in CLIL, a wider usage can be conceived. The tool, the observations made, and its application in CLIL teacher training and professional development might be of importance to foreign language teachers as well. It may serve as an example of how content and language integrating principles can facilitate language learning, and of how teachers can stimulate content-based language learning activities in foreign language curricula. Both content and language teachers can learn a lot from each other, and trainers and researchers, in turn, can learn a lot from both.

\section{Acknowledgements}

The authors would like to thank Nina Spada, Do Coyle and two anonymous reviewers for their thorough and valuable comments on an earlier version of this paper. They also thank the teachers and students from the three CLIL schools that participated in the study for their time, effort and confidence. This 
study was financially supported by the Dutch Ministry of Education, coordinated by the National Pedagogic Centres (LPC).

\section{Correspondence}

Any correspondence should be directed to Rick de Graaff, Universiteit Utrecht, IVLOS, Postbus 80127, Utrecht 3508TC, The Netherlands (r.degraaff. uu.nl).

\section{References}

Baetens Beardsmore, H. (ed.) (1993) European Models of Bilingual Education. Clevedon: Multilingual Matters.

Baker, C. (1993) Foundations of Bilingual Education and Bilingualism. Clevedon: Multilingual Matters.

Bialystok, E. (1990) Communication Strategies. Oxford: Blackwell.

Brumfit, C.J. and Johnson, K. (eds) (1979) The Communicative Approach to Language Teaching. Oxford: Oxford University Press.

Burgess, J. and Etherington, S. (2002) Focus on grammatical form: explicit or implicit. System 30 (4), 433-458.

Bygate, M., Skehan, P. and Swain, M. (2001) Researching Pedagogic Tasks. Second Language Learning, Teaching and Testing. Harlow, Essex: Pearson.

Crookes, G. and Gass, S.M. (1993) Tasks in a Pedagogical Context. Integrating Theory E Practice. Clevedon: Multilingual Matters.

Cummins, J. and Swain, M. (1986) Bilingualism in Education: Aspects of Theory, Research and Practice. New York: Longman.

De Bot, K. (1996) The psycholinguistics of the output hypothesis. Language Learning 46 (3), 529-555.

De Bot, K. (2002) CLIL in the European context. In D. Marsh (ed.) CLIL/EMILE - The European Dimension: Actions, Trends and Foresight Potential (pp. 29-32). DG Education \& Culture, European Commission.

De Graaff, R. and Housen, A. (in press) Investigating the effects and effectiveness of L2 instruction. In M. Long and C. Doughty (eds) The Handbook of Second and Foreign Language Teaching. Malden, MA: Blackwell Publishing.

Doughty, C.J. (2003) Instructed SLA: Constraints, compensation and enhancement. In C.J. Doughty and M.H. Long (eds) Handbook of Second Language Acquisition (pp. 256-310). Oxford: Blackwell.

Doughty, C. and Williams, J. (1998) Focus on Form in Classroom Language Acquisition. New York: Cambridge University Press.

Echevarria, J., Vogt, M.E. and Short, D. (2000) Making Content Comprehensible for English Learners: The SIOP Model. Boston: Allyn \& Bacon.

Ellis, R. (1999) Learning a Second Language Through Interaction. Amsterdam: John Benjamins.

Ellis, R. (2001) Form-focused Instruction and Second Language Learning. Malden, MA: Blackwell.

Ellis, R. (2003) Task-based Language Learning and Teaching. Oxford: Oxford University Press.

Ellis, R. (2005) Instructed Second Language Acquisition; a Literature Review. Wellington, New Zealand: Ministry of Education.

Eurydice European Unit (2005) Key data on teaching languages at schools in Europe 2005. http://www.eurydice.org/portal/page/portal/Eurydice/showPresentation? pubid=071EN Accessed 10.03.07.

Genesee, F. (1987) Learning Through Two Languages. Studies of Immersion and Bilingual Education. Rowley, MA: Newbury House.

Harley, B. (1993) Instructional strategies and SLA in early French immersion. Studies in Second Language Acquisition 15, 245-259. 
Housen, A. and Pierrard, M. (2005) Instructed second language acquisition. Introduction. In A. Housen and M. Pierrard (eds) Investigations in Instructed Second Language Acquisition (pp. 1-26). Berlin, New York: Mouton de Gruyter.

Huibregtse, I. (2001) Effecten en didactiek van tweetalig voortgezet onderwijs in Nederland [Effects and Pedagogy of Bilingual Secondary Education in the Netherlands]. Utrecht: WCC.

Johnson, K. (1982) Communicative Syllabus Design and Methodology. Oxford: Pergamon.

Johnson, K. and Swain, M. (1997) Immersion Education: International Perspectives. Cambridge: Cambridge University Press.

Klein, W. (1986) Second Language Acquisition. Cambridge: Cambridge University Press.

Krashen, S.D. (1985) The Input Hypothesis: Issues and Implications. London: Longman.

Littlemore, J. (2001) An empirical study of the relationship between cognitive style and the use of communication strategy. Applied Linguistics 22 (2), 241-265.

Long, M. (1991) Focus on form: A design feature in language teaching methodology. In K. De Bot, R. Ginsberg and C. Kramsch (eds) Foreign Language Research in Crosscultural Perspective (pp. 40-52). Amsterdam: John Benjamins.

Lyster, R. (2004) Differential effects of prompts and recasts in form-focused instruction. Studies in Second Language Acquisition 26, 399-432.

Lyster, R. and Ranta, L. (1997) Corrective feedback and learner uptake; negotiation of form in communicative classrooms. Studies in Second Language Acquisition 20, 37-66.

Maljers, A. and Wooning, C. (2003) Survey on Content and Language Integrated Learning. Alkmaar, the Netherlands: Europees Platform voor het Nederlandse Onderwijs.

Marsh, D. and Langé, G. (2000) Using Languages to Learn and Learning to Use Languages. Jyväskylä, Finland: UniCOM.

Marsh, D. (ed.) (2002) CLIL/EMILE - The European Dimension: Actions, Trends and Foresight Potential. DG Education \& Culture, European Commission.

Marsh, D. (2003) The relevance and potential of content and language integrated learning (CLIL) for achieving MT +2 in Europe. ELC Information Bulletin 9 (4). On WWW at http://web.fu-berlin.de/elc/bulletin/9/en/marsh.html.

Marsh, D. (ed.) (2005) Insights E Innovation Special Educational Needs in Europe. The Teaching and Learning of Languages. European Commission, January.

Norris, J. and Ortega, L. (2000) Effectiveness of L2 instruction: A research synthesis and quantitative meta-analysis. Language Learning 50, 417-528.

Nunan, D. (1989) Understanding Language Classrooms. A Guide for Teacher-initiated Action. New York: Prentice Hall.

Obadia, A. (1996) La formation du professeur d'immersion française: une perspective historique. The Canadian Modern Language Review 52, 271-284.

Pawley, C. (1985) How bilingual are French immersion students? The Canadian Modern Language Review 41, 865-876.

Poulisse, N. (1989) The Use of Compensatory Strategies by Dutch Learners of English. Enschede: Sneldruk.

Prabhu, M.S. (1987) Second Language Pedagogy. Oxford: Oxford University Press.

Skehan, P. (1998) A Cognitive Approach to Language Learning. Oxford: Oxford University Press.

Spada, N. (1997) Form-focussed instruction and second language acquisition: A review of classroom and laboratory research. Language Teaching 30, 73-87.

Swain, M. (1995) Three functions of output in second language learning. In G. Cook and B. Seidlhofer (eds) Principle and Practice in Applied Linguistics: Studies in Honour of H.G. Widdowson. Oxford: Oxford University Press.

Swain, M. and Lapkin, S. (1995) Problems in output and the cognitive processes they generate. A step towards second language learning. Applied Linguistics 16, 371-391.

Wesche, M. (1993) Discipline-based approaches to language study: Research issues and outcomes. In M. Krueger and F. Ryan (eds) Language and Content (pp. 80-95). Lexington, MA: D.C. Heath.

Wesche, M.B. and Skehan, P. (2002) Communicative, task-based, and content-based language instruction. In R.B. Kaplan (ed.) The Oxford Handbook of Applied Linguistics (pp. 207-228). Oxford: Oxford University Press. 
Westhoff, G.J. (1991a) Increasing the effectiveness of foreign language reading instruction (Part 1). ADFL Bulletin 22 (2), 29-36.

Westhoff, G.J. (1991b) Increasing the effectiveness of foreign language reading instruction (Part 2). ADFL Bulletin 22 (3), 28-32.

Westhoff, G.J. (2004) The art of playing a pinball machine. Characteristics of effective SLA-tasks. Babylonia 12 (3), 52-57.

Willis, J. (1996) A Framework for Task-based Learning. Harlow: Longman.

Wolff, D. (2000) Languages across the curriculum: A way to promote multilingualism in Europe. In C. Gnutzmann (ed.) Teaching and Learning English as a Global Language: Native and Non-Native Perspectives (pp. 171-184). Tübingen: Stauffenburg Verlag. 